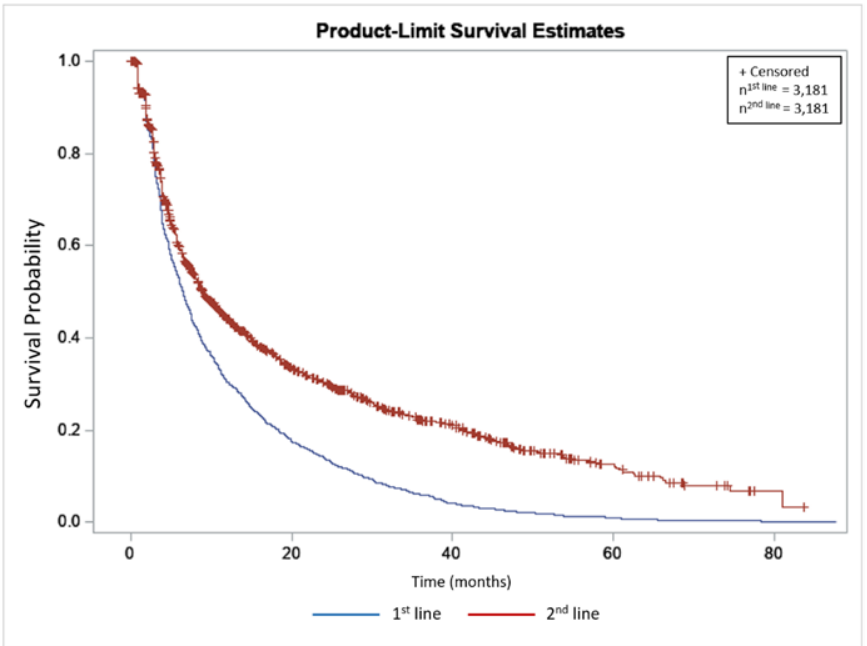

Figure 1. Persistence, among cyclers, with subcutaneous Tumor Necrosis Factor- $a$ inhibitors treatment for IA by line of treatment

risk of discontinuing SC-TNFi treatment were significantly lower in $2^{\text {nd }}$ line compared to $1^{\text {st }}$ line (Hazard Ratio [HR]; $0.60[0.57,0.63]$ and 0.59 [0.56, $0.62]$, respectively). This finding was also consistent across IA indications (Table 1).

Conclusion: In this preliminary analysis of IA patients cycling on SC-TNFis, persistence was greater in $2^{\text {nd }}$ line compared to $1^{\text {st }}$ line treatment. The finding was consistent across all IA indications. Hence, IA patients who fail to respond, lose response, or for other reasons discontinue their $1^{\text {st }}$ line treatment may still benefit from switching to an alternative SC-TNFi as a $2^{\text {nd }}$ line therapy.

Disclosure of Interests: Johan Dalén Consultant of: Merck \& Co., Inc. in conjunction with the development of this abstract. JD is an employee of ICON plc. ICON plc have received funding from several pharmaceutical companies involved in the marketing products for treatment of inflammatory arthritis., Amy Puenpatom Shareholder of: shareholder at Merck \& Co, Inc, Employee of: Employed at Merck \& Co, Inc., Karin Luttropp Consultant of: Merck \& Co., Inc. in conjunction with the development of this abstract. $\mathrm{KL}$ is an employee of ICON plc. ICON plc have received funding from several pharmaceutical companies involved in the marketing products for treatment of inflammatory arthritis., Christopher Black Shareholder of: I own shares of MSD, Employee of: I am an employee of MSD

DOI: 10.1136/annrheumdis-2020-eular.687

\section{FRI0514 USE OF OPIATE FOR HIP AND KNEE OSTEOARTHRITIS BEFORE AND AFTER JOINT REPLACEMENT SURGERY}

C. Lao ${ }^{1}$, D. Lees ${ }^{2}$, D. White ${ }^{3}$, R. Lawrenson ${ }^{1,3} .{ }^{1}$ University of Waikato, Hamilton, New Zealand; ${ }^{2}$ Tauranga Hospital, Tauranga, New Zealand; ${ }^{3}$ Waikato Hospital, Hamilton, New Zealand

Background: Osteoarthritis of the hip and knee is one of the most common causes of reduced mobility. It also causes stiffness and pain. Opioids can offer pain relief but is usually used for severe acute pain caused by major trauma or surgery. The use of opioids for relief of chronic pain caused by arthritis has increased over the last few decades.[1]

Objectives: This study aims to investigate the use of strong opiates for patients with hip and knee osteoarthritis before and after joint replacement surgery, over a 13 years period in New Zealand.

Methods: This study included patients with osteoarthritis who underwent publicly funded primary hip and knee replacement surgeries in 2005-2017 in New Zealand. These records were identified from the National Minimum Dataset (NMD). They were cross referenced with the NZJR data to exclude the admissions not for primary hip or knee replacement surgeries. Patients without a diagnosis of osteoarthritis were excluded.

The PHARMS dataset was linked to the NMD to identify the use of strong opiates before and after surgeries. The strong opiates available for community dispensing in New Zealand and included in this study are: dihydrocodeine, fentanyl, methadone, morphine, oxycodone and pethidine. Use of opiate within three months prior to surgery and within 12 months post-surgery were examined by gender, age group, ethnicity, Charlson Comorbidity Index score and year of surgery. Differences by subgroup was examined with Chi- square test. Logistic regression model was used to calculate the adjusted odds ratios of strong opiate use before and after surgery compared with no opiate use.

Results: We identified 53,439 primary hip replacements and 50,072 primary knee replacements with a diagnosis of osteoarthritis. Of patients with hip osteoarthritis, 6,251 (11.7\%) had strong opiate before hip replacement surgeries and $11,939(22.3 \%)$ had opiate after surgeries. Of patients with knee osteoarthritis, $2,922(5.8 \%)$ had strong opiate before knee replacement surgeries and 15,252 $(30.5 \%)$ had opiate after surgeries.

The probability of patients with hip and knee osteoarthritis having opiate decreased with age, increased with Charlson comorbidity index score, and increased over time both before and after surgeries. Male patients with hip and knee osteoarthritis were less likely to have opiate than female patients both before and after surgeries. New Zealand Europeans with hip and knee osteoarthritis were more likely to receive opiate than other ethnic groups prior to surgeries, but were less likely to have opiate than Asians post-surgeries.

Patients who had opiate before surgeries were more likely to have opiate after surgeries than those who did not have opiate before surgeries. The odds ratio was 8.34 (95\% confidence interval $(\mathrm{Cl}):$ 7.87-8.84) for hip osteoarthritis and 11.94 (95\% Cl: 10.84-13.16) for knee osteoarthritis after adjustment for age, gender, ethnicity, year of surgery and Charlson comorbidity index score. Having opiate prior to surgeries also increased the probability of having opiate for 6 weeks or more after surgeries substantially. The adjusted odds ratio was 21.46 (95\% Cl: 19.74-23.31) for hip osteoarthritis and 27.22 (95\% Cl: 24.95-29.68) for knee osteoarthritis.

Conclusion: Preoperative opiate holidays should be encouraged. Multiple strategies need to be used to develop analgesic plans that allow adequate rehabilitation, without precipitating a chronic opiate dependence. Clinicians would also benefit from clear guidelines for prescribing strong opiates.

References:

[1] Nguyen, L.C., D.C. Sing, and K.J. Bozic, Preoperative Reduction of Opioid Use Before Total Joint Arthroplasty. J Arthroplasty, 2016. 31(9 Suppl): p. 282-7.

Disclosure of Interests: None declared

DOI: 10.1136/annrheumdis-2020-eular.1359

\begin{tabular}{|l|l}
\hline FRI0515 & MATERNAL AND PERINATAL OUTCOMES IN \\
WOMEN WITH RHEUMATIC DISEASES - A 10-YEAR \\
EXPERIENCE FROM A PORTUGUESE TERTIARY \\
CENTRE
\end{tabular}

A. R. Cruz-Machado ${ }^{1,2}$, S. C. Barreira ${ }^{1,2}$, P. Martins ${ }^{1,2}$, M. Centeno $^{3}$, C. Araújo ${ }^{3}$, L. Pinto ${ }^{3}$, S. Capela ${ }^{1,2} .{ }^{1}$ Hospital de Santa Maria, Serviço de Reumatologia e Doenças Ósseas Metabólicas, Lisboa, Portugal; ${ }^{2}$ Instituto de Medicina Molecular (IMM), Unidade de Investigação em Reumatologia, Lisboa, Portugal; ${ }^{3}$ Hospital de Santa Maria, Departamento de Obstetrícia, Ginecologia e Medicina da Reprodução, Lisboa, Portugal

Background: Pregnant women with rheumatic diseases (RD) represent a population at a higher risk for adverse pregnancy outcomes (APO). At our unit, these patients (pts) are surveilled at a high-risk pregnancy clinic, by both rheumatologists and obstetricians.

Objectives: To assess pregnancy outcomes in pts with RD surveilled at our unit over the last decade.

Methods: Single-centre observational retrospective study of pregnant women with RD followed at a portuguese tertiary centre between 2009 to 2019.

Results: Overall, 353 pregnancies (preg) in 295 pts with RD were managed at our unit. Table 1 summarizes clinical data and the main APO recorded. Systemic lupus erythematous (SLE) was the leading diagnosis followed by spondyloarthritis ( $\mathrm{SpA}$ ) and rheumatoid arthritis (RA). Antiphospholipid syndrome (APS) was diagnosed in $49(13.9 \%)$ preg. We documented 284 (78\%) live births (9 twin preg), $32(10 \%)$ miscarriages, $7(2 \%)$ elective abortions, 2 stillbirths $(0.6 \%)$ and 2 ectopic preg; 35 (10\%) of the overall preg were lost to follow up before delivery. Miscarriages occurred predominantly in pts with APS (34\%). Fetal growth restriction (FGR) was recorded in $6 \%$ of preg, more than $1 / 3$ of those in pts with APS. Preeclampsia (PE) complicated a total of $10(4 \%)$ preg, 3 of those with superimposed HELLP syndrome, with SLE and APS accounting for $60 \%$ of the cases. Preterm births (15.5\%) occurred mainly in APS, SLE and juvenile idiopathic arthritis (JIA) pts. Neonatal lupus ensued in $3(3.8 \%)$ preg positive for anti-Ro/La antibodies. No neonatal deaths were recorded. SpA and RA represented the diseases which flared the most considering both pregnancy and the postpartum period. 
Table 1. Pregnancy outcomes by disease

\begin{tabular}{|c|c|c|c|c|c|c|c|c|}
\hline $\begin{array}{l}\text { Main } \\
\text { diagnosis }\end{array}$ & $\mathrm{N}, \%$ & $\begin{array}{l}\text { Gest age } \\
\text { at delivery } \\
\text { (weeks) }\end{array}$ & Miscarr & FGR & PE & Preterm births & $\begin{array}{c}\text { Flares in } \\
\text { preg }\end{array}$ & $\begin{array}{c}\text { Flares in } \\
\text { PP }\end{array}$ \\
\hline SLE & $\begin{array}{l}116, \\
32.9\end{array}$ & $38 \pm 2.3$ & $\begin{array}{c}13 / 110 \\
11.8\end{array}$ & $\begin{array}{c}6 / 82 \\
7.3\end{array}$ & $\begin{array}{c}5 / 78 \\
6.4\end{array}$ & $\begin{array}{c}15 / 76 \\
21.1\end{array}$ & $\begin{array}{c}16 / 92 \\
17.4\end{array}$ & $\begin{array}{c}5 / 79 \\
6.3\end{array}$ \\
\hline SpA & $\begin{array}{c}60 \\
17\end{array}$ & $39 \pm 2.6$ & $\begin{array}{c}2 / 55 \\
3.6\end{array}$ & $\begin{array}{c}5 / 44 \\
11.4\end{array}$ & $\begin{array}{c}1 / 45 \\
2.2\end{array}$ & $\begin{array}{c}5 / 40 \\
12.5\end{array}$ & $\begin{array}{c}18 / 40 \\
45\end{array}$ & $\begin{array}{c}5 / 23 \\
21.7\end{array}$ \\
\hline RA & $\begin{array}{c}51 \\
14.4\end{array}$ & $39 \pm 1.2$ & $\begin{array}{l}6 / 49 \\
12.2\end{array}$ & $\begin{array}{c}1 / 35 \\
2.9\end{array}$ & $\begin{array}{c}1 / 33 \\
3\end{array}$ & $\begin{array}{c}1 / 29, \\
3.4\end{array}$ & $\begin{array}{c}10 / 37 \\
27\end{array}$ & $\begin{array}{l}7 / 30 \\
23.3\end{array}$ \\
\hline Vasculitis & $\begin{array}{l}25 \\
7.1\end{array}$ & $38 \pm 1.8$ & $\begin{array}{c}1 / 24, \\
4.2\end{array}$ & $\begin{array}{c}1 / 21 \\
4.8\end{array}$ & $\begin{array}{c}0 / 19 \\
0\end{array}$ & $\begin{array}{c}4 / 21, \\
19\end{array}$ & $\begin{array}{l}7 / 23 \\
30.4\end{array}$ & $\begin{array}{c}2 / 17 \\
11.8\end{array}$ \\
\hline $\begin{array}{l}\text { Primary } \\
\text { APS }\end{array}$ & $\begin{array}{l}22, \\
6.2\end{array}$ & $38 \pm 1.6$ & $\begin{array}{l}3 / 22 \\
13.6\end{array}$ & $\begin{array}{c}1 / 17 \\
5.9\end{array}$ & $\begin{array}{c}1 / 16 \\
6.3\end{array}$ & $\begin{array}{c}2 / 16 \\
12.5\end{array}$ & NA & NA \\
\hline JIA & $\begin{array}{l}17, \\
4.8\end{array}$ & $38 \pm 2.5$ & $\begin{array}{c}1 / 17 \\
5.9\end{array}$ & $\begin{array}{c}0 / 12 \\
0\end{array}$ & $\begin{array}{c}0 / 11 \\
0\end{array}$ & $\begin{array}{l}4 / 12, \\
33.3\end{array}$ & $\begin{array}{l}2 / 13 \\
15.4\end{array}$ & $\begin{array}{l}1 / 8 \\
12.5\end{array}$ \\
\hline UCTD & $\begin{array}{l}15, \\
4.2\end{array}$ & $39 \pm 1.5$ & $\begin{array}{l}2 / 15, \\
13.3\end{array}$ & $\begin{array}{c}0 / 11 \\
0\end{array}$ & $\begin{array}{c}1 / 10 \\
10\end{array}$ & $\begin{array}{c}1 / 11 \\
9.1\end{array}$ & $\begin{array}{c}0 / 15 \\
0\end{array}$ & $\begin{array}{c}0 / 15 \\
0\end{array}$ \\
\hline $\begin{array}{l}\text { Primary } \\
\text { Sjögren } \\
\text { Syndrome }\end{array}$ & $\begin{array}{l}12, \\
3.4\end{array}$ & $39 \pm 1.4$ & $\begin{array}{c}0 / 11 \\
0\end{array}$ & $\begin{array}{c}0 / 9 \\
0\end{array}$ & $\begin{array}{c}0 / 10 \\
0\end{array}$ & $\begin{array}{l}1 / 9 \\
11.1\end{array}$ & $\begin{array}{l}1 / 8 \\
12.5\end{array}$ & $\begin{array}{c}0 / 6 \\
0\end{array}$ \\
\hline Others & $\begin{array}{l}35, \\
9.9\end{array}$ & $38 \pm 2.3$ & $\begin{array}{l}4 / 31 \\
12.9\end{array}$ & $\begin{array}{c}2 / 20 \\
10\end{array}$ & $\begin{array}{c}1 / 18 \\
5.6\end{array}$ & $\begin{array}{l}3 / 18 \\
16.7\end{array}$ & $\begin{array}{l}4 / 27 \\
14.8\end{array}$ & $\begin{array}{c}1 / 22 \\
4.5\end{array}$ \\
\hline Total & $\begin{array}{c}353, \\
100\end{array}$ & $38 \pm 2.2$ & $\begin{array}{c}32 / 334, \\
9.6\end{array}$ & $\begin{array}{c}16 / 251, \\
6.4\end{array}$ & $\begin{array}{c}10 / 240, \\
4.2\end{array}$ & $\begin{array}{c}36 / 232, \\
15.5\end{array}$ & $\begin{array}{c}58 / 255 \\
22.7\end{array}$ & $\begin{array}{c}21 / 200 \\
10.5\end{array}$ \\
\hline
\end{tabular}

Secondary

diagnosis

APS

\begin{tabular}{lcccccccc} 
APS & 27 & $37 \pm 2.7$ & $8 / 26$, & $5 / 16$, & $2 / 12$, & $5 / 15$, & NA & NA \\
& & & 30.8 & 31.3 & 16.7 & 33.3 & & \\
Sjögren & 9 & \multirow{2}{*}{$3 \pm 2.5$} & $1 / 9$, & $1 / 7$, & $0 / 7$, & $3 / 6$, & NA & NA \\
Syndrome & & & 11.1 & 14.3 & 0 & 50 & &
\end{tabular}

Legend - gest: gestational; miscarr: miscarriages; NA - not applicable; PP: postpartum; preg: pregnancy; UCTD - Undifferentiated connective tissue disease. Continuous variables are presented as mean + SD. Categorical variables as $n / m N, \%-\operatorname{modified}(m) N$ stands for total $N$ - (not applicable+missing data); "Others" accounts for diagnosis with $\mathrm{N} \leq 6$, such as APS non criteria, mixed connective tissue disease, myositis, overlap syndromes, Still's disease and systemic sclerosis.

Conclusion: In pregnant women with $\mathrm{RD}$, it is of vital importance to be aware of the increased risk for APO. In our cohort, APS and SLE were the conditions most associated with APO, while SpA and RA were responsible for most maternal flares. Nevertheless, the majority of these pts, surveilled by a multidisciplinary team, had successful gestations.

Disclosure of Interests: None declared

DOI: 10.1136/annrheumdis-2020-eular.2125

\section{FRI0516 CANCER SCREENING IN WOMEN WITH SYSTEMIC LUPUS ERYTHEMATOSUS}

S. Bruera ${ }^{1}$, R. Zogala ${ }^{2}$, X. Lei ${ }^{3}$, X. Pundole ${ }^{3}$, H. Zhao ${ }^{3}$, S. Giordano ${ }^{3}$, J. Hwang ${ }^{3}$, M. Suarez-Almazor ${ }^{3} .{ }^{1}$ Baylor College of Medicine, Houston, United States of America; ${ }^{2}$ Comunity Hospital - Grand Valley Rheumatology, Grand Junction, United States of America; ${ }^{3}$ University of Texas MD Anderson Cancer Center, Houston, United States of America

Background: Systemic lupus erythematosus (SLE) is a chronic autoimmune disease that carries an increased risk for both viral illnesses and malignancies, including a greater risk for both human papilloma virus (HPV) infection and cervical cancer. Due to this increased risk, the American Society of Colposcopy and Cervical Pathology guidelines for SLE patients recommend more frequent cervical cancer screening. Few studies have examined patient characteristics associated with decreased cervical cancer screening in patients with autoimmune disease, specifically SLE.

Objectives: To estimate cervical cancer screening rates in women with recently diagnosed SLE, and to identify characteristics associated with decreased screening.

Methods: We identified women with an initial diagnosis of SLE in the United States MarketScan Commercial Claims and Encounter (CCAE, age 18-64) administrative claims database. We included patients with at least three claims with a lupus diagnosis (first and last at least $>90$ days apart), no lupus claims within the year before initial claim, and who had been on antimalarial drugs for at least 90 days. We excluded all patients with a previous claim for hysterectomy.

Cervical cancer screening was ascertained using diagnosis and procedure codes within 1 year before and 2 years after the first SLE claim. Our covariates included the year of first SLE claim (2001-2014), age at first SLE claim, comorbidity score, insurance type, geographical region, and prescriptions for multiple types of corticosteroids. Control patients included age-matched females without autoimmune disease. Univariate comparison and multivariate logistic regression models were built to evaluate determinants of screening.

Results: We included 4,316 SLE patients (median age 45) and 86,544 control patients. The screening rate in SLE patients was $73.4 \%$ vs $58.5 \%$ in the controls $(P<0.001)$. The screening rate was $71 \%$ in 2001 , increased to $75 \%$ in 2004, then decreased to $70 \%$ in 2014 (trend $P=0.005$ ). In the multivariate model the following factors were associated with decreased cervical cancer screening: year of first SLE claim 2012-2014 versus 2001-2005 (odds ratio (OR) $0.67,95 \%$ confidence interval $(\mathrm{Cl}) 0.53-0.84, \mathrm{P}<0.001$ ); older age $61-64$ versus $21-30$ (OR $0.27,95 \% \mathrm{Cl} 0.19-0.39, \mathrm{P}<0.001$ ); comorbidity score of $\geq 2$ versus $<2$ (OR $0.71,95 \% \mathrm{Cl} 0.6-0.83, \mathrm{P}<0.001$ ); and use of corticosteroids for $\geq 90$ days versus $<90$ days (OR $0.73,95 \% \mathrm{Cl} 0.59-0.9, \mathrm{P}=0.003$ ). Insurance type and geographical region were not associated with cervical cancer screening.

Conclusion: About three quarters of women with SLE underwent cervical cancer screening within 3 years of their first lupus claim, at higher rates than controls. However, there was a concerning downward trend in screening rates in recent years. In addition, higher risk populations for cervical cancer (older age, increased comorbidities, and longer duration of corticosteroids) had lower screening rates. These findings highlight the need to enhance education for healthcare providers to improve utilization of screening in women with SLE at high risk of cervical cancer. Disclosure of Interests: Sebastian Bruera: None declared, Richard Zogala: None declared, Xiudong Lei: None declared, Xerxes Pundole: None declared, Hui Zhao: None declared, Sharon Giordano: None declared, Jessica Hwang Grant/ research support from: MERCK grant funding unrelated to SLE., Maria Suarez-Almazor: None declared

DOI: 10.1136/annrheumdis-2020-eular.3824

\section{FRI0517 \\ POSSIBLE EARLY DETECTION OF ADVERSE EVENTS USING A STRUCTURED, STANDARD, 60-SYMPTOM CHECKLIST ON A MULTIDIMENSIONAL HEALTH ASSESSMENT QUESTIONNAIRE (MDHAQ)}

K. Schroeder ${ }^{1}$, S. Abu Mehsen ${ }^{1}$, I. Castrejon ${ }^{2}$, T. Pincus ${ }^{1} .{ }^{1}$ Rush University, Rheumatology, Chicago, United States of America; ' ${ }^{2}$ Gregorio Marañón Hospital, Rheumatology, Madrid, Spain

Background: Adverse events of medications are reported to account for $5 \%$ of hospital admissions in the USA, including $10 \%$ in the elderly, despite extensive warnings to patients by health professionals and pharmacies concerning the problem. Some adverse events are relatively obvious, such as a severe rash or severely abnormal laboratory test. However, many adverse events are common symptoms, such as headache or fatigue, which may not necessarily be recognized as adverse events, particularly in elderly patients with many comorbidities. In clinical trials and other clinical research, a structured, standard, protocol-driven symptom checklist is recorded according to the "scientific method." In routine care, by contrast, recognition and recording of adverse events is elicited by health professionals at patient encounters or contact initiated by patients between visits, as "subjective" medical history information, which may be highly variable. Use of a standard symptom checklist on an electronic patient questionnaire has been reported in oncology, pulmonology and other specialties, but not in rheumatology. A multidimensional health assessment questionnaire (MDHAQ) includes a standard 60-symptom checklist, to recognize comorbidities, provide a review of systems, and serve on a fibromyalgia assessment screening tool (FAST3) as a clue to identify patients with fibromyalgia. The MDHAQ 60-symptom checklist can identify new symptoms after initiation of a medication which may be adverse events.

Objectives: To analyze an MDHAQ 60-symptom checklist as a cost-effective approach to recognize medication-associated adverse events.

Methods: All patients at one site complete an MDHAQ at each visit, which includes a standard, structured 60-symptom checklist, in addition to RAPID3 (routine assessment of patient index data) and FAST3. Paper MDHAQs from routine care are scanned into an Epic electronic medical record (EMR) and copied into a data repository for retrospective analyses. A list of common adverse events of many specific DMARDs (disease-modifying antirheumatic drugs) and biological agents used to treat rheumatoid arthritis (RA) was compiled from websites of the FDA, pharmaceutical companies, and Up-to-date.® Most listed symptoms are found on the structured MDHAQ 60-symptom checklist. A retrospective review of scanned MDHAQs at the first visit was conducted to recognize the presence or absence of self-reported symptoms which were listed as common adverse events for specific DMARDs on the MDHAQ 60-symptom checklist using simple descriptive statistics. Only methotrexate (Mtx) is presented here due to space limitations.

Results: All symptoms listed as adverse events of specific DMARDs were reported at higher frequencies in 379 DMARD-treated RA patients or $153 \mathrm{Mtx}$ treated patients, compared to 149 DMARD-naïve patients (Table). More than $30 \%$ of DMARD-treated patients reported headache and/or unusual fatigue, $27 \%$ anxiety; $10-20 \%$ cough, dizziness, hair loss, nausea, skin rash or hives, 